\title{
Subsídios, medidas compensatórias e medidas de salvaguarda. Sua disciplina no GATT, na OMC, no Direito Interno e no Direito Comunitário
}

\author{
Simone Tatsch \\ Doutoranda em Direito Econômico na USP \\ Advogada em São Paulo
}

INTRODUÇÃO

I PARTE - Os subsídios enquanto elemento de influência na livre concorrência e as medidas compensatórias.

A) Os subsídios:1.1.1. Conceito e origem;1.1.2. Espécies;1.1.3. Isenções e subsídios impróprios;1.1.4. Disciplina no GATT e na OMC;1.1.5. Disciplina no Direito Interno;1.1.6. Disciplina no Direito Comunitário.

B) 1.2. As medidas compensatórias:1.2.1. Conceito e natureza jurídica;1.2.2. Disciplina no GATT e na OMC;1.2.3. Disciplina no Direito Interno;1.2.4. Disciplina no Direito Comunitário.

II PARTE - As medidas de salvaguarda.

A) Conceito e disciplina. 2.1. Disciplina no GATT e na OMC;2.2. Disciplina no Direito Interno;2.3. Disciplina no Direito Comunitário.

CONCLUSÃO

BIBLIOGRAFIA

\section{Introdução}

O estudo dos subsídios, das respectivas medidas compensatórias e das medidas de salvaguarda interessa à quase totalidade dos Estados, em sua maioria economias capitalistas ou em mudança para esse sistema. E, nesse sentido, o valor fundamental e pressuposto de existência dessas economias é o princípio da livre concorrência. Por conseguinte, é de vital im-

portância o estudo das causas ou instrumentos que podem afetá-la, bem como das formas de correção desses desvios.

Com efeito, quando do surgimento do Liberalismo, no século XVIII, a livre concorrência era o princípio normativo que imperava, alheio a quaisquer outros valores, que não a liberdade. No então laissez-faire laissez-passer, 
laissez-aller, acreditava-se que o mercado por si mesmo era capaz de se auto-regular, de forma a manter o sistema capitalista.

Contudo, no século $\mathrm{XX}$, percebeu-s que o mercado sozinho não era capaz de garantir a livre concorrência, pois empresas fortes conseguiam destruir outras, dando início a monopólios. Percebeu-se que o sistema capitalista na sua versão puramente liberal era imperfeto, sendo a participação do Estado importante, para a manutenção do sistema econômico.

Além disso, também nesse século, novos valores foram introduzidos nas constitu ções, os quais deveriam também reger o sistema capitalista, tais como a preocupação com meio ambiente e com o consumidor. Paralelamente, os Estados passaram a intervir na economia, seja para regulá-la, seja para participa diretamente das atividades econômicas, alterando o livre jogo das forças do mercado.

Mesmo com esses elementos de cunho social a limitar o princípio da livre concorrência ele é a base necessária, condição essencial do sistema capitalista, que impera em quase todo o globo. Assim, tanto no plano do Direito Internacional, quanto no do Direito Interno e, mais recentemente, no plano do Direito Comunitário, os fatores que alteram, negativamente, a livre concorrência, bem como as respectivas medidas de correção têm sido estudados normatizados

Tais fatores podem ser causados por atos dos próprios concorrentes ou por atos dos Estados, na busca da proteção de seus mercados e das empresas nacionais. No primeiro caso, temos o dumping, compreendido como a venda de produtos abaixo do seu preço de custo ou do seu preço normal. Essa prática visa a eliminar os concorrentes mais fracos, que não conseguem fornecer ao mercado produtos aptos a competir com aqueles. No segundo caso, temos os subsídios fornecidos pelos Estados aos produtores nacionais, os quais facilitam a produção ou a venda, através de redução de seus custos, o que necessariamente refletirá no preço final da mercadoria a ser exportada, tornando-a, artificialmente, mais competitiva.

A primeira parte desse trabalho é dedicada ao estudo dos subsídios e das suas espécies. Logo em seguida, serão analisadas as medidas aplicáveis para a correção do desequilíbrio da concorrência, originado pelos mesmos, nas hipóteses em que eles são vedados, isto é, as chamadas medidas ou direitos compensatórios ${ }^{1}$.

Já a segunda parte do trabalho é dedicada às medidas de salvaguarda, as quais não são fundadas na existência de dumping ou no fornecimento de subsídios vedados, mas apenas visam a proteger a indústria nacional, frente a um volume considerável de importação de determinado produto, dentro das regras de mercado. Veremos que essas medidas, numa primeira observação, poderiam ser consideradas contrárias ao princípio da livre concorrência. Contudo, essa é apenas uma análise superficial.

Também na primeira e segunda parte serão analisadas as respectivas disposições no General Agreements on Tarifes and Trade GATT, até 1994 e, a partir de 1995, as disposições dos acordos firmados sob a égide da Or-
A doutrina e os próprios textos normativos internacionais e nacionais usam indistintamente os termos "direitos" e "medidas" compensatórias. Os franceses utilizam o termo "direito" (droit compensateur) e os americanos termo "medida" (countervailing duty/measure). Contudo, muito embora se tratem de verdadeiros direitos potestativos, preferimos utilizar a expressão "medidas" compensatórias, conforme a versão na língua ingles dos tratados internacionais, mantendo-se assim a mesma expressão que é dada às "medidas de salvaguarda" (safeguards measures).

Revista da Faculdade de Direito da UFRGS, v. 21, Março/2002 ganização Mundial de Comércio-OMC ${ }^{2}$. No plano do Direito interno, o enfoque dado ao estudo dos institutos foi o do comércio internacional, isto é, serão discutidas, fundamentalmente, as disposições nacionais aplicáveis às exportações e importações. Por fim, serão apontados alguns aspectos desses institutos no Direito Comunitário ${ }^{3}$.

Assim, ao final, teremos uma ampla visão, por certo sem esgotar o assunto, do conceito, tratamento e aplicação dos três institutos objetos do presente estudo - subsídios, medidas compensatórias e medidas de salvaguarda - nos campos do Direito Internacional (GATT/ OMC), do Direito Interno brasileiro e do Direito Comunitário.

IPARTE -Os subsídios enquan-

to elemento de influência na livre concorrência e as medidas compensatórias

\subsection{Os subsídios}

\subsubsection{Conceito e origem}

Já na Idade Média, a comuna medieval intervinha, claramente, no domínio econômico e social, fiscalizando e estimulando os ofícios burgueses e exercendo certo protecionismo em relação aos produtos externos à comuna. $\mathrm{A}$ mesma tradição de intervenção econômica foi mantida na Idade Moderna, após a formação dos Estados Nacionais, com o mercantilismo ${ }^{4}$. Na Idade Contemporânea, no ápice do Estado

2 O GATT foi assinado em 1947, logo após a Segunda Guerra Mundial, com o fim de regular o comércio internacional, tendo entrado em vigor em 01.01.1948. Na naquele momento era intenção das partes criar um organismo internacional, tal qual o Fundo Monetário Internacional - FMI ou a própria ONU, mas o que se conseguiu foi apenas o tratado (GATT), que possuía caráter provisório. Várias discussões e acordos de interpretação do GATT ocorrerem entre 1948 e 1994 (Dilton Round, Kennedy Round, Tokio Round. e Uruguay Round). Nessa última, em 1994, foi enfim criada a Organização Mundial de Comércio - OMC (World Trade Organization - WTO). Aqui é interessante transcrever a crítica de Giorgio Sacerdorf àqueles que afirmam que o GATT transformou-se na OMC: "Ainda que de fato apropriado, não é juridicamente correto falar-se em 'transformação' do GATT em OMC. A secretaria do GATT dependia sempre da Comissão interina para a ITO (ICITO), instituída pela Conferência da ONU sobre Comércio e o desenvolvimento realizada em Havana em 1947-48 e mantinha operante para essa finalidade. O artigo 16.2 do Acordo da OMC dispõe que, 'na medida do praticável, a secretaria do GATT transformar-se-á em secretaria da OMC e o diretor geral das partes contratantes do GATT-1947 funcionará como diretor geral da OMC até que a Conferência Ministerial tenha nomeado um diretor geral, em conformidade ao parágrafo 2 do artigo VI deste acordo'. A conferência GATT/OMC de 7-8 de dezembro de 1994, na qual foi decidida a entrada em vigor do Acordo WrO de 1 de janeiro de 1995 (cf. o artigo 3 do Ato Final de Marrakesh), decidiu entre outros a coexistencia provisoria dos dois acordos, por um peso, à espera de que a ratifiççá da WTO estivesse completa, a transferencia dos bens, obrigaçōos, arquivos e

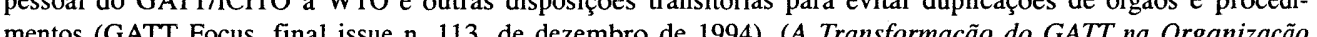
Mustos (OATT Fous, hal issue n. 113, de dezeo ou Integrac Co Mudiol pelo Comecio? A OMC o o Brasil. Ed. LT, São Paulo, 1998, p. 5069,

Muito embora no Mercosul, no momento uma união aduaneira imperfeita, não exista, propriamente, um direito comunitário, visto que não há órgão supraestatal na instituição, alguns pontos referentes aos seus tratados pertinentes ao presente estudo serão também indicados nos capítulos de Direito Comunitário.

4 Preliminarmente, Pierre Deyon assim conceitua o mercantilismo: "conjunto das teorias e das práticas de intervenção econômica que se desenvolveram na Europa moderna desde a metade do século XV." (Ob. cit., p. $11 / 12)$

Revista da Faculdade de Direito da UFRGS, v. 21, Março/2002 
Liberal Clássico, a intervenção econômica passou a ser vista como desnecessária e indevida. As forças do mercado, através da livre concorrência, levada à sua interpretação mais extrema, garantiriam o desenvolvimento e a manutenção do sistema capitalista.

Contudo, no século XX, restou evidente a incapacidade da livre concorrência absoluta, atingida através do afastamento do Estado da ordem econômica, de garantir efetividade a outros valores que então estavam surgindo, tais como os direitos sociais. A própria manutenção do sistema capitalista pressupõe a existência de mercados consumidores, os quais não existem se não houver um mínimo de desenvolvimento econômico e social, o que não poderia ser conseguido sem a ajuda estatal, principalmente, nos países subdesenvolvidos.

Nesse contexto, temos duas formas básicas de atuação estatal na atividade econômica - a direta e a indireta. No primeiro caso, o Estado assume o papel de agente econômico, isto é, atua como se fosse um empresário privado, produzindo, ele mesmo, bens e serviços (públicos ou não) $)^{5}$. No segundo caso, O Estado

apenas normatiza e regula a economia, sem que haja atuação ou intervenção direta ${ }^{6}$. No campo da normatização, está a fiscalização, e no da regulação, estão o planejamento e o incentivo ${ }^{7}$.

Assim, os subsídios, sob o ponto de vista do direito econômico, são formas de incentivo da atividade econômica, sendo, por conseguinte, atuação estatal indireta. Para a melhor compreensão do que são eles, é ideal analisá-los também do ponto de vista financeiro, porquanto neste é encontrada a forma de realização das funções econômicas do Estado. Com efeito, sob esse enfoque, os subsídios, normalmente ${ }^{8}$, representam despesas públicas, que surgem devido a necessidades econômicas coletivas públicas relativas ${ }^{9}$, isto é, necessidade de incentivos econômicos (bem escasso), de determinado setor da sociedade, no qual o Estado tem um justificado interesse constitucional ou legal, sem que esse incentivo seja imprescindível à satisfação ou existência do próprio Estado.

Portanto, tratando-se de despesa pública, os subsídios devem estar previstos em lei ${ }^{10}$ e em conformidade com os princípios econômi-

${ }^{5}$ A Constituição Federal brasileira de 1988 prevê a intervenção direta no art. 173 e a atuação direta estatal (serviços públicos) no art. 175.

${ }^{6}$ Eros Roberto Grau diferencia o termo atuação de intervenção estatal. A atividade econômica estatal poderia ser classificada em sentido estrito e em sentido amplo. No primeiro caso, estaríamos diante de uma intervenção estatal, pois o termo intervenção denota uma atividade dentro do campo de titularidade de outrem, no caso, do setor privado. À intervenção corresponderia a atuação direta na economia. Por outro lado, a atividade económica estatal em sentido amplo abrangeria os serviços públicos e a atuação normativa e reguladora do Estado. Muito embora os serviços públicos sejam forma de atuação direta na atividade econômica, năo representaria uma intervenção, pois a titularidade da atividade é do próprio Estado, conforme indicam as constituições. (Ob. cit., p. 122/135)

${ }^{7}$ A atuação estatal indireta está prevista no art. 174 da Constituição Federal brasileira de 1988, nos seguintes termos: "Art. 174. Como agente normativo e regulador da atividade econômica, o Estado exercerá, na forma da lei, as funções de fiscalização, incentivo e planejamento, sendo este determinante para o setor público e indicativo para o setor privado.

${ }^{8}$ Referimo-nos "normalmente", pois no capítulo 1.1.3, trataremos dos subsídios impróprios.

${ }^{9}$ Conforme classificação de Walter Paldes Valério. Ob. cit., p. 15/21.

${ }^{10}$ Com efeito, a Constituição Federal brasileira de 1988, no art. 165, ao tratar dos orçamentos, exige no parágrafo $6^{\circ}$ que o projeto de lei orçamentária seja acompanhado de demonstrativo regionalizado do efeito, sobre as receitas e despesas, decorrente, entre outros benefícios, dos subsídios.

Revista da Faculdade de Direito da UFRGS, v. 21, Março/2002 cos constitucionais, para ser, obviamente do ponto de vista interno, legais e constitucionais. Por outro lado, o beneficiário usufrui o incentivo através do ato administrativo que realiza a despesa, o que reitera a necessidade de previsão legal.

Com isso, buscamos formular um conceito de subsídio que o identifica como um forma de atuação econômica estatal indireta voltada para o fomento ou incentivo de determinada atividade econômica nacional, realiza$\mathrm{da}$, normalmente, através de ato administrativo que autoriza determinada despesa pública não reembolsável ao Estado pelo beneficiário do incentivo.

Entretanto, os subsídios não são a única forma de incentivo da atividade econômica ao lado deles estão outros benefícios, tais como os creditícios, os financeiros, os fiscais. O que difere um subsídio de outro benefício é o fato de que os subsídios não são reembolsáveis ${ }^{11}$.

Todavia, os acordos internacionais denominam subsídios também os outros benefícios, mesmo que reembolsáveis. Assim, para fins de análise, podemos dizer que há o conceito stricto sensu e outro lato sensu de subsídios, este abrangendo todos os benefícios dados pelo Estado à indústria nacional, mesmo que reembolsáveis.

Do ponto de vista do comércio internacional, os subsídios latu sensu, que influenciam as exportações, serão, fundamentalmente, $o$ objeto de estudo. Assim, chamaremos, a partir de agora, apenas de subsídios, os subsídios lato sensu. "Nesse sentido também entende Luis Cabral de Moncada, in verbis: "O subsídio é uma expressão genérica que
abrange um conjunto diversificado de providências administrativas possuindo, no entanto, um denominador
comum: o tratar-se de atribuiçóes pecuniárias unilaterais a favor dos sujeitos económicos sem que estes fiquem comum: o tratar-se de atribuições pecuniárias unilaterais a favor dos sujeitos económicos sem que estes fiquem constituídos da obrigação de reembolso. É por essa razão que também se chama o subsídio subvenção, comparticipação, prêmio, etc. É, pois, em atenção ao critério da natureza jurídica da situação do beneficiário, consoante este fique ou não sujeito ao reembolso (a fundo perdido) que se distingue o subsídio das restantes " (Ob. cit., p. 356)

${ }^{12}$ Esse ponto será analisado no item 1.2.3 do presente trabalho

Revista da Faculdade de Direito da UFRGS, v. 21, Março/2002
Mister mencionar que a legalidade e do subsídio não irá interessar ao direito internacional, o qual está preocupado em remediar tais incentivos, para proteger a livre concorrência internacional. Pode-se dizer apenas que a galidade do subsídio representa mais um insrumento pelo prejudicado de combate ao mes-

\subsubsection{Espécies}

Podemos classificar os subsídios sob varios critérios. Contudo, aqui escolhemos dois enfoques que interessam ao comércio internacional. O primeiro deles diz respeito às suas formas de fornecimento, e o segundo refere-se à
ermissão ou não do subsídio, frente às normas da OMC.

Com efeito, quanto à forma de fornecireta. A forma direta representa uma despesa do Estado, trata-se de uma prestação positiva esrenúncia de receita por parte do Estado, isto é, rata-se de uma prestação negativa. Esse é um abrir uma discussão pertinente a respeito das isenções serem ou não subsídios ${ }^{12}$.

A segunda classificação baseia-se nos ritérios postos pela OMC, para permitir ou não subsídios. Define os subsídios como acionáveis não acionáveis.

Enquadram-se na primeira hipótese aqueles subsídios específicos, isto é, para os quais mento do subsídio, ela pode ser direta ou indi- 
a autoridade outorgante ou a legislação limitam, explicitamente, o seu acesso à apenas uma empresa, um grupo de empresas, um ramo específico de produção, uma área geográfica ou estejam vinculados ao desempenho do exportador ou ao uso de produtos domésticos ${ }^{13}$

São considerados subsídios não acionáveis, portanto, aqueles que não forem específicos, os quais estejam baseados em disposições que, objetivamente, estabeleçam critérios para acesso geral ao benefício e deixem claro o montante a ser recebido.

Ligia Maura Costa ${ }^{14}$, basicamente sob esse mesmo critério, apresenta classificação um pouco distinta. Segundo a jurista, os subsídios seriam proibidos, recorríveis e irrecorrivei ou permitidos. Subsídios proibidos seriam aqueles baseados no desempenho da exportação e no uso de produtos domésticos. Seriam recorríveis, os subsídios que podem gerar efeitos prejudiciais à concorrência ${ }^{15}$. Por fim, autora indica os subsídios irrecorríveis ou permitidos, os quais não restringem o comércio ou distorcem seus efeitos, isto é, aqueles não específicos e os específicos, mas voltados às atividades de pesquisa, manutenção do meio am biente ou desenvolvimento de determinadas regiões.

Essa classificação deriva do disposto pela OMC, contudo enfatiza alguns critérios que, no nosso entender, não são úteis. Os possíveis efeitos danosos à livre concorrência, so-

mente podem ser constatados, após uma análise profunda do subsídio concedido. Nesse sentido, a priori, não seria pertinente classificar de irrecorrível um subsídio, quando para classificá-lo, é necessário justamente recorrer dele.

Pela análise das espécies, percebemos que nem todos os subsídios são passíveis de gerar medidas compensatórias, ou melhor, nem todos os subsídios são vedados no âmbito internacional.

\subsubsection{Isenções e subsídios impróprios}

Conforme mencionado, há subsídios que podem ser, indiretamente, concedidos, isto é, sem que o governo tenha uma despesa pública. Nessas hipóteses, há uma renúncia de receita pelo poder público, que ocorre através de isenções ${ }^{16}$. Esses são os subsídios que chamaremos de impróprios.

Todavia, nem tudo o que chamamos de isenções podem ser consideradas subsídios impróprios.

Não serão verdadeiras isenções fiscais aquelas renúncias a receitas fiscais que nada mais representem do que uma delimitação negativa da hipótese de incidência tributária. Isso o ocorre, quando o fundamento da renúncia fiscal estiver na justiça distributiva, traduzida na capacidade contributiva. Nesse sentido, quando o legislador ou constituinte renuncia a determinada receita tributária, mas o fundamento dessa renúncia estiver na consideração feita da capacidade do contribuinte de suportar aquele ônus, isto é, na capacidade contributiva do mesmo, não estaremos di ante de uma isenção fiscal (subsídio impróprio $)^{17}$.

Nessa linha está o princípio do destino, segundo o qual o país não deve exportar tributo, sob pena de o consumidor final pagar mais do que se tivesse comprado produto do seu país, afinal estaria exposto ao duplo pagamento de tributo. Isso nada mais representa do que a preocupação com capacidade contributiva $^{18}$.
Assim, poderiam ser considerados subsídios, no caso, impróprios, as verdadeiras isenções fiscais, as quais não representam delimitações negativas da hipótese de incidência, derivadas da observância da capacidade contributiva do beneficiado, em atendimento à justiça distributiva.

\subsubsection{Disciplina no GATT e na OMC}

$\mathrm{O}$ art. VI do GATT/47 era destinado às matérias referentes ao dumping e às medidas compensatórias, referentes aos subsídios. No item 3 do referido artigo, havia a definição de subsídio, o qual era compreendido como qualquer benefício, direto ou indireto, sobre a manufatura, produção ou exportação do produto

${ }^{13}$ Essa mesma definição pode ser encontrada nos arts. $5^{\circ}$ e $6^{\circ}$ do Decreto $1.751 / 95$, que regulamentou a Lei $n$. 9.019/95, a qual dispõe sobre a aplicação dos direitos previstos no Acordo Antidumping e no de Subsídios e Direitos Compensatórios da OMC.

${ }^{14}$ Ob. cit. p. 88.

${ }^{15}$ Assim leciona a autora: "Esse tipo de subsídio não é, necessariamente, prejudicial, mas pode sê-lo em algumas circunstâncias. Nenhum País-Membro deve utilizar essa categoria de subsídio para comprometer os interesses de um outro Membro, isto é, prejudicar a indústria doméstica desse país ou causar-lhe um sério prejuízo." (Ob. cit. p. 88)

${ }^{16}$ Mister mencionar que aqui também estão enquadradas as imunidades, consideradas como isenções previstas no próprio texto constitucional.

17 “É mérito de Klaus Vogel ter desenvolvido em 1977 e de Klaus Tipke ter complementado uma Metodologia jurídica de distinção entre as isenções tributárias e as delimitações negativas da hipótese de incidência. Vogel descobriu que o critério decisivo de distinção estaria na finalidade de tais normas: enquanto as isenções tributárias são normas de finalidade fiscal e as delimitações negativas da hipótese de incidência são normas de finalidade extrafiscal. A distinção entre normas de finalidade fiscal (isençōes) e normas de finalidade extrafiscal (delimitações negativas da hipótese de incidência), por sua vez é um processo hermenêutico teleológico (VOGEL, Klaus, "Die Abschichtung von Rechtsfolgen im Steuerrecht", StuW 2/1977, p. 106 e ss.), baseado no qual ele desenvolveu sua "estratificação objetiva segundo a função". Segundo tal teoria a tarefa comum a todas as leis tributárias é arrecadar recursos, ou pelo menos dar condiçōes, para a cobertura das necessidades financeiras do Estado. Vogel percebeu que, além dessa função arrecadatória, as normas tributárias teriam também (1) a função de repartição da necessidade financeira segundo critérios de justiça distributiva (função distributiva) ou
(2) a função de perseguir determinadas finalidades político econômicas (função dirigista). Vogel conclui então (2) a função de perseguir determinadas finalidades político econômicas (função dirigista). Vogel conclui então que a base para a "estratificação objetiva" teria de ser aquela norma que dentre as possibilidades a serem examinadas de alguma forma se deixa compreender como reprodução da justiça distributiva. Trata-se daquela justiça aristotélica que segundo Norbert Horn "contempla a comunidade. Ela ordena que todos seja tratados igualmente, trabalha geometricamente" (HORN, Norbert, "Einführung in die Rechtswissenschaft und Rechtsphilosophie", Heidelberg, C.F. Muller, 1996, p. 141.), "ou seja, que sejam tratados os igesis iguam

${ }^{18}$ Esse princípio pode ser identificado no art. $4^{\circ}$, II B do Decreto 1.751/95, que dispõe: "Art. $4^{\circ}$. Para os fins deste Decreto, considera-se que existe subsídio quando é conferido um benefício em função das hipóteses a seguir:

II - haja contribuição financeira por um governo ou órgão público, no interior do território do país exportador, denominado a partir daqui 'governo', nos casos em que:

b sejam perdoadas ou deixem de ser recolhidas receitas públicas devidas (incentivos fiscais, entre outros), não sendo consideradas subsidios as isençoes, en favor dos produtos desthados à exportaçăa, de impostos ou taxas habitualmente aplicados ao produto similar quando destinado ao consumo interno, nem a devoluçao ou abono de tais impostos ou taxas, desde que o valor não exceda os totais devidos, de acordo com o art. XVI do GATT/ 94 e os Anexos I a III do Acordo sobre Subsídios e Medidas Compensatórias;"

Revista da Faculdade de Direito da UFRGS, v. 21, Março/2002 
exportado, incluindo qualquer benefício ao transporte de um produto particular ${ }^{19}$. Caso o subsídio subsumisse a nesses casos, seria possível a aplicação de medidas compensatórias, se houvesse também comprovação de dano à indústria nacional.

O art. XVI do GATT/47, na Seção A, também tratava de subsídios, adicionando ao seu conceito qualquer forma de sustentação de renda ou preço, destinada a aumentar exportação de qualquer produto ou a reduzir a importação dentro de seu território. $O$ Estado deveria notificar os outros signatários, explicando o montante do subsídio e sua necessidade. Interessante salientar que nesse artigo, a Seção A refere-se aos subsídios em geral (Subsidies in General), para os quais o tratado exigia a notificação. Contudo, a Seção B do mesmo artigo, referia-se aos subsídios exportados, estes objeto de medidas compensatórias na forma do art. VI do tratado.

Em 1979 foi feita a Rodada Tóquio, na qual foi elaborado um Código de Subsídios, que alargou o conceito do mesmo e previu sistema de consulta e resolução de controvérsias. Nesse período, não houve uma larga aceitação pelos países do código, considerando que somente 24 assinaram-no ${ }^{20}$
Já no cenário da OMC, foi feito um novo código de subsídios, na Rodada Uruguai, em 1994. Contrariamente ao que ocorreu na Rodada Tóquio, a todos os países membros da OMC esse novo código passou a ser aplicável.

A principal inovação trazida por ele foi uma definição mais clara, no próprio texto, do conceito de subsídio. Conforme o art. $1^{\circ}$ haverá subsídio quando (1) houver contribuição financeira por um governo ou órgão público no interior do território membro, como, por exemplo, transferência direta ou potencial, de recursos governamentais, renúncia fiscal, fornecimento de bens e serviços, exceto os de infra-estrutura, etc; ou houver qualquer forma de sustentação de preços, no sentido do art. XVI do GATT 94; e com isso configure vantagem.

\subsubsection{Disciplina no Direito Interno}

No Brasil, a Lei n. 9.019 de 30 de março de 1995 dispõe sobre os direitos previstos no Acordo de Subsídios e Medidas Compensatórias. O Decreto n. 1.751/95 regulou essa lei, praticamente mantendo os mesmos termos do Acordo de Subsídios e Medidas Compensatórias vigentes na $\mathrm{OMC}$

19 "3. No countervailing duty shall be levied on any product of the territory of any contracting party imported into the territory of another contracting party in excess of an amount equal to the estimated bounty or subsidy determined to have been granted, directly or indirectly, on the manufacture, production or export of such product in the country of origin or exportation, including any special subsidy to the transportation of a particular product...

${ }^{20}$ Cf. Welber Barral. Subsidios e Medidas Compensatórias na OMC. In Guerra Comercial ou Integração Mundial pelo Comércio? A OMC e o Brasil. Ob. cit. p. 373.

Revista da Faculdade de Direito da UFRGS, v. 21, Março/2002

A definição de subsídio está no art. $4^{\circ}$ do referido decreto ${ }^{21}$. Contudo, seguindo a classificação da OMC, nem tudo o que for enquadrado como subsídio é vedado. Serão acionáveis, somente os subsídios específicos (a determinada empresa, grupo de empresas, determinada região, etc). Não serão acionáveis aqueles destinados a fomentar pesquisa, de senvolvimento de região pobre, conforme critérics objetivos postos em lei, e os destinados a promover adaptações em instalações visando cumprir exigências que visem proteção ambiental.

Podemos dizer que os subsídios concedidos aos componentes de produto importado (upstream subsidies) podem ser acionáveis, mas não o serão aqueles concedidos de forma generalizada (general available subsidies).

\subsubsection{Disciplina no Direito Comunitário}

Ainda na Comunidade Econômica Européia - CEE já havia ampla normatização, regulando a concessão de subsídios, a qual praticamente permanece vigendo. O sistema europeu considerava subsídio qualquer benefício à exportação concedido no país de origem, direta ou indiretamente, à produção de mercadoria que vá circular pelo território da Comunidade (art. 3-, no $1^{\circ}$, do Regulamento oㅜ 2.176, de 1984). A CEE possuía uma lista de subsídios sujeitos a medidas compensatórias, sem incluir os subsídios concedidos aos componentes do produto importado (upstream subsidies), mas abrangendo aqueles concedidos de forma generalizada (general available subsidies) $^{22}$.
21 "Para os fins deste Decreto, considera-se que existe subsídio quando é conferido um benefício em função das hipóteses a seguir:

I - haja, no país exportador, qualquer forma de sustentação de renda ou de preços que, direta ou indiretamente, contribua para aumentar exportações ou reduzir importações de qualquer produto; ou

II - haja contribuição financeira por um governo ou órgão público, no interior do território do país exportador, denominado a partir daqui 'governo', nos casos em que:

a) a prática do governo implique transferência direta de fundos (doações, empréstimos, aportes de capital, entre outros) ou potenciais transferências diretas de fundos ou obrigações (garantias de empréstimos, entre outros); ou

b) sejam perdoadas ou deixem de ser recolhidas receitas públicas devidas (incentivos fiscais, entre outros), não sendo consideradas como subsídios as isenções, em favor dos produtos destinados à exportação, de impostos ou taxas habitualmente aplicados ao produto similar quando destinado ao consumo interno, nem a devolução ou abono de tais impostos ou taxas, desde que o valor não exceda os totais devidos, de acordo com o art. XVI do GATT/1994 e os Anexos I a III do Acordo Sobre Subsídios e Medidas Compensatórias; ou

c) o governo forneça bens ou serviços além daqueles destinados à infra-estrutura geral, ou quando adquira bens; ou

d) o governo faça pagamentos a um mecanismo de fundo, ou instrua ou confie à entidade privada a realizar uma ou mais das funcões descritas nas alíneas anteriores, as quais seriam normalmente incumbência do governo, e cuja atuação não difira, de modo significativo, da prática habitualmente seguida pelos governos.

${ }^{22}$ Interessante mencionar que, nos Estados Unidos, em 1984, uma Lei de Tarifas e Comércio (Trade and Tariffs Act) veio determinar que o cálculo do montante dos subsídios apurados deve incluir também aqueles concedidos aos componentes do produto importado (upstream subsidies). Prosseguindo nesse mesmo alargamento do às medides compen às medidas compensatórias, aqueles concedidos de forma generalizada (general available subsidies)

Revista da Faculdade de Direito da UFRGS, v. 21, Março/2002 
Com efeito, o conceito de subsídio hoje na União Européia é bastante amplo, pois, praticamente, qualquer auxílio estatal é considerado subsídio ${ }^{23}$, sendo vedados aqueles que afetem as trocas comerciais entre Estados-Membros, concedidos pelos Estados ou provenientes de recursos estatais, independentemente da forma que assumam, falseando a concorrência ou favorecendo certas empresas ou certas produções ${ }^{24}$. É também requisito para que o subsídio seja vedado a especificidade do mesmo, de maneira semelhante a $\mathrm{OMC}^{25}$.

Excepcionando esse amplo conceito, o art. 92 do Tratado de Roma, permite subsídios que tenham por fim o desenvolvimento de áreas com nível de vida anormalmente baixo, onde exista grave situação de subemprego, a realização de projetos de interesse comum dos Estados-Membros, os destinados a promover a cultura e a conservação do patrimônio histórico, etc. Quaisquer outros subsídios podem ser considerados compatíveis, através de proposta da Comissão, apresentada ao Conselho, que proferirá uma decisão a respeito por maioria qualificada $^{26}$.

Em relação aos países externos à União, as regras da OMC são aplicáveis.

${ }^{23}$ Massimo Merolla. Ob. cit. p. 7

${ }^{24}$ Cf. Umberto Celli Júnior. Ob. cit. p. 221/222.

25 "Para que recaiam na alçada da proibição do art. 92, n. 1, os auxílios do Estado devem favorecer especificamente certas empresas ou produções (sectores produtivos). Significa isto que se deve distinguir ajudas chamadas 'medidas gerais', isto é, das intervenções dos poderes públicos com vocação geral que se aplicam de modo uniforme à economia de um país no seu conjunto, como são, em regra, os casos do normativos fiscais gerais, das leis de segurança social ou das medidas de política monetária. O elemento distintivo dos auxílios estatais é nos dado pelo seu caráter selectivo e, as mais das vezes, discriminatório. Tendem ainda a ser de aplicação temporária, ao contrário das 'medidas gerais' que têm um caráter duradouro. Contudo, a fronteira entre ambas não é, na prática, simples de determinar." (António Carlos Santos. Maria Eduarda Gonçalves e Maria Manue Leito Marques. Ob. cit., p. 418)

${ }^{26}$ A esse respeito, vide Luís Cabral de Moncada. Ob. cit. p. 341.

${ }^{27}$ Preferimos nos referir a medidas compensatórias ao invés de direitos compensatórios, seguindo os termos da (countervailing measures), o que não encontra desconformidade com a nossa legislação, que ora denominam medidas compensatórias (Decreto n. 1.751/95), ora direitos compensatórios (Lei n. 9.019/95).

Revista da Faculdade de Direito da UFRGS, v. 21, Março/2002 lei. A aplicação de medidas compensatórias é ato administrativo discricionário, não estado sequer o Estado importador (lesado) obrigado a aplicar as medidas.

Conforme o art. 151, I da CF/88 e do art. 10 do CTN, os tributos devem ser gerais e uniformes no território nacional. Entretanto, isso também não ocorre com as medidas compensatórias, pois é possível aplicar diferentes montantes a diferentes casos, apenas observando o limite máximo, que é o valor do subsídio.

Assim, resta claro que as medidas compensatórias não têm natureza tributária.

Por outro lado, poder-se-ia questionar se não seriam, então, sanção por ato ilícito. Todavia, pela mesma razão de ser a aplicação da medida ato discricionário do Estado importador, não seria possível aceitar que sua natureza jurídica seja essa. Afinal, a sanção sempre deve ser aplicada pelo Estado frente a atos ilícitos.

Com efeito, seguindo a posição de Tércio Sampaio Ferraz Júnior, José Ferreira da Rosa e Maura Grinberg ${ }^{28}$, temos que as medidas compensatórias são imposições paratarifárias de direito econômico internacional, que visam equilibrar o mercado interno atingido pelo produto importado subsidiado.

\subsubsection{Disciplina no GATT e na OMC}

O GATT/47 previa a aplicação de medidas compensatórias no art. VI. Conforme item 3 desse artigo, as medidas compensatórias não poderiam exceder o montante do subsídio concedido, princípio esse lógico, considerando que

o objetivo não é penalizar o Estado que forneceu o subsídio, mas apenas equilibrar as relações comerciais afetadas pelo benefício. Seguindo o princípio do destino, também não poderiam ser objeto de medidas compensatórias as isenções ou abonos de tributos incidentes sobre produto igual ao exportado, quando destinado para o mercado interno.

O dano, elemento essencial para a aplicação de medidas compensatórias, era compreendido como a ameaça ou efetivo dano à industria nacional ou o retardamento de seu estabelecimento, devido ao subsídio fornecido ao produto importado por aquele determinado país.

Caso a demora pudesse causar dano de difícil reparação, era possível aplicar medidas compensatórias provisórias, desde que imediatamente reportadas aos Estados contratantes, e esses não rejeitassem as medidas.

O Acordo sobre Subsídios e Medidas Compensatórias do GATT/94 não alterou, profundamente, o que já estava disposto no GATT/ 47, mas apresenta, em geral, normas mais completas e rígidas, no caso da aplicação de medidas compensatórias provisórias.

No que tange ao requisito do dano, o acordo estabelece que, mesmo havendo dano à indústria doméstica do país importador, tratando-se de produto oriundo de país em desenvolvimento, se o subsídio representar até $3 \%$, ad valorem, do preço do produto importado ${ }^{29}$ não será possível aplicar medidas compensatórias. Esse benefício aos países em desenvolvimento perdurará por 8 anos da data da assinatura do acordo, esgotando-se, portanto, em 2002.

28 "É possível dizer, em suma, que os direitos anti-dumping e compensatórios constituem conteúdo de normas de direito econômico internacional, que impõe ao produto exportado/importado condições de acesso ao Mercado do país importador, que podem ser o pagamento dos direitos ou a assunção de obrigações por parte dos exportar en eliminação do dumping ou do subsídio, tudo isso de modo que a comercialização seja condizeneconomia." (Ob. cit. p. 95)

${ }^{29}$ No cálculo do montante do subsídio são descontados os gastos necessários para a aquisição do benefício e os tributes aplicados para neutralizar o subsídio. 
Conforme o acordo, indústria doméstica é o conjunto de produtores nacionais do produto similar ou como aqueles dentre eles cuja produção conjunta constitua a maior parte da produção nacional total desse produto. Duas exceções são feitas a esse conceito. A primeira é na hipótese dos produtores estarem vinculados ao exportador ou ao importador do produto. Nesse caso, será considerada indústria doméstica os demais produtores. A segunda exceção refere-se à hipótese de concentração de importações de produtos subsidiados causando dano a uma parte específica do mercado. A solução aqui é considerar indústria doméstica somente aquele mercado, dividindo o território nacional, para fins de aplicação de medidas compensatórias.

Contudo, a alteração sensivel entre o GATT/47 e o Acordo de Subsídios e Medidas Compensatórias da OMC é percebida nos requisitos de aplicação de medidas compensatórias provisórias. Nos termos atuais, elas somente poderão ser aplicadas, após sessenta dias do início das investigações, se forem determinadas, preliminarmente, a existência de subsídio e do dano à industria nacional e se as medidas foram imprescindíveis, para evitar danos suplementares à indústria nacional. Nesse caso, podem ser exigidas as medidas compensatórias provisórias ou pode ser feito depósito em dinheiro ou apresentada fiança no valor do subsídio dado. O prazo máximo de duração dessas medidas é de 4 meses. Já a medida compensatória definitiva não pode ultrapassar o prazo de 5 anos a contar da data da sua aplicação.

Todos os procedimentos de investigação da existência de subsídios e a posterio aplicação de medidas compensatórias são da competência do país importador. Contudo, OMC exige que sejam observados princípios, hoje comuns ao direito processual, tais como possibilidade de defesa, publicidade dos atos e possibilidade de recurso. Esgotadas as vias domésticas, pode o conflito ser levado a OMC.

\subsubsection{Disciplina no Direito Interno}

Conforme mencionado, no Brasil, a Lei n. 9.019 de 30 de março de 1995 dispõe sobre os direitos previstos no Acordo de Subsídios e Medidas Compensatórias. O Decreto n. 1.751/ 95 regulou essa lei, praticamente mantendo os mesmos termos do Acordo de Subsídios e Medidas Compensatórias vigentes na OMC. Contudo, importante mencionar que a Câmara de Comércio Exterior - CAMEX exerce papel fundamental no país na aplicação e fiscalização das medidas compensatórias.

\subsubsection{Disciplina no Direito Comunitário}

A aplicação de medidas compensatórias na União Européia se assemelha à forma prevista na OMC. Contudo existem algumas especificidades que é interessantes salientar.

Medidas compensatórias provisórias podem ser adotadas pela Comissão, desde que, da análise preliminar dos fatos (1) reste comprovada a existência de auxílio estatal, (2) que haja elementos que comprovem o prejuízo ao país importador e (3) que a medida seja urgente. A decisão da Comissão pode ser revista pelo Conselho.

Confirmados os fatos, a Comissão remete ao Conselho uma proposta de medida compensatória definitiva, a qual é aplicada, através de um regulamento do Conselho.

A aplicação de medida compensatória provisória ou definitiva pode ser substituída por uma ordem de cessar a exportação ou por um acordo, através do qual, o produto exportado tem seu preço aumentado, para cobrir o montante do auxílio estatal.

Mesmo na hipótese de ter havido um acordo, substituindo uma medida compensatória provisória, apurados os fatos, é possível ao Conselho aplicar uma medida compensatória definitiva.
II PARTE - As medidas de salvaguarda

\subsection{Conceito}

As medidas de salvaguarda, diferentemente das medidas compensatórias, não visam recuperar o equilíbrio entre as trocas comerciais entre dois países, devido a uma má prática comercial. As medidas de salvaguarda visam proteger determinada área de produção nacional, afetada por um aumento significativo no volume de importações de determinado produto, que esteja gerando danos a indústria nacional ou retardando a implantação dessa produção no país importador. Isso é feito, normalmente, pela redução ou eliminação da importação.

Note-se que esse aumento das importações, passível de gerar medidas de salvaguarda, não decorre da existência de subsídio ou dumping. Há uma prática comercial justa que, mesmo assim, gera dano à indústria do país importador, porque esse não consegue compe$\mathrm{tir}^{30}$. Portanto, poderíamos dizer que o produto importado respeita as regras de mercado, mas pode gerar danos a uma indústria nacional por ser mais competitivo, seja por ter melhor preço e/ ou qualidade.

Isso justifica o caráter excepcional e temporário das salvaguardas, pois na verdade são medidas protecionistas, aparentemente contrárias ao princípio da livre concorrência.
Contudo, há um duplo fundamento para a aplicação dessas medidas. O primeiro é que o aumento das importações, normalmente, se deve à observância dos tratados referentes ao comércio, que tendem a facilitar as transferências entre os países. Ocorre que isso pode se tornar injusto, pois permite que, em alguns casos, poucos produtores beneficiem-se desses acordos em detrimento de outros que ainda não estão suficientemente preparados para competir. $\mathrm{O}$ segundo fundamento é que não é interessante à livre concorrência permitir que poucos atuem no mercado. Assim, o fim último das medidas de salvaguarda, embora tenham caráter protecionista, é justamente a manutenção da livre concorrência ${ }^{31}$.

\subsection{Disciplina no GATT e na OMC}

O GATT/47 previa a aplicação das medidas de salvaguarda no art. XIX, sob o nome de Ação Emergencial sobre Importações de Determinados Produtos (Emergency Action on Imports of Particular Products).

Ponto característicos das salvaguardas é que elas não poderiam ser discriminatórias, isto é, não poderia haver a suspensão da importação de determinado produto apenas em relação a um país signatário, mas deveria ser dos produtos de todos países da mesma forma. Essa regra fez com que as medidas de salvaguarda fossem pouco utilizadas. Os países preferiam concluir acordos industria a indústria, para buscar resolver o problema. Eram os chamados acordos de restrição voluntários
${ }^{30}$ Nesse sentido, Georde Holliday ensina: "Safeguards are distinct from other trade remedy measures, such as those aimed at dumping, subsidies and other unfair trade practices. While the latter are designed to counter existing distortions to efficient trade patterns, safeguards are used to impose restrictions on fairly traded goods." (Ob. cit., p. 156)

${ }^{31}$ Nesse sentido, vide George Holliday. Ob. cit. p. 156. 
(Voluntary Restraint Agreements - VRAs). Isso gerou um descontrole na aplicação das medidas e uma prática comercial claramente discriminatória.

Além disso, o GATT/47 não previa perí odo máximo de duração das medidas, o que acabou por desvirtuá-las.

Na Rodada Uruguai, quando da assinatura do Acordo sobre Medidas de Salvaguarda (Agreement on Safeguards) a solução para essa situação foi buscada. O princípio da não discriminação foi mantido, de sorte que a medida aplicável a um produto, independentemente do país de origem. Contudo, poderá haver a aplicação de medidas de salvaguarda, seletivamente, se for provado pelo país importador que as importações de alguns membros estão muito além das proporções razoáveis.

Outra inovação do acordo foi o estabelecimento de um prazo para as medidas. As medidas devem durar o tempo necessário para permitir os ajustes necessários na indústria nacional e/ou para remediar os danos. Entretanto, esse período não pode ultrapassar os quatro anos, prorrogáveis por, no máximo, mais quatro. De qualquer forma, contando com o período de aplicação das medidas provisórias e prorrogação, esse prazo de oito anos deve ser observado.

Também é prevista no acordo a chamada Cláusula da Paz, que tem por fim evitar que o país que aplicou as medidas sofra retaliações. Contudo, essa proteção somente pode perdurar por três anos. É mister salientar que esse período é menor do que o permitido para a duração das medidas. Portanto, podemos perceber que o próprio acordo estimula que as medidas não durem por mais do que três anos, demonstrando sua maior preocupação em afastar protecionismos do que permitir que as indústrias nacionais tornemse igualmente competitivas.
Finalmente, as salvaguardas também não podem restringir as importações abaixo do nível médio dos últimos três anos. Essa regra retrata a rigidez que o acordo trouxe na aplicação das salvaguardas. Na verdade, mais uma vez implica uma baixa da efetividade das medidas, no que tange a possibilidade de permitir que a indústria nacional faça os ajustes necessários, para que consiga competir. Afinal, as importações continuarão, e na média calculada sobre um exíguo período, no qual as chances de as importações terem sido altas (gerando inclusive o pedido das medidas) são muito grandes.

\subsection{Disciplina no Direito Interno}

As medidas de salvaguardas estão reguladas no Brasil pelo Decreto n. 1.488, de 12 de maio de 1995.

Conforme esse decreto, compete ao Ministro da Indústria e Comércio, juntamente com o Ministro da Fazenda, aplicar as medidas de salvaguarda.

Conforme $o$ art. $3^{\circ}$ do decreto, estão legitimados a pedir a aplicação das medidas a Secretaria de Comércio Exterior-SECEX, demais órgãos e entidades interessadas do Governo Federal, bem como empresas ou associações de empresas que produzam o produto objeto da medida requerida.

Quanto ao conteúdo do decreto, da mesma forma que ocorre com o Decreto $\mathrm{n}$ $1.751 / 95$, referente aos subsídios e medidas compensatórias, ele praticamente apenas internaliza as disposições do Acordo sobre Salvaguardas da OMC

\subsection{Disciplina no Direito Comunitário}

O Tratado de Assunção, o qual criou o Mercado Comum do Sul - MERCOSUL, preve a aplicação de medidas de salvaguarda a serem aplicáveis aos produtos constantes das listas de produtos a terem tarifas reduzidas ${ }^{32}$.

\section{Conclusão}

A livre concorrência é elemento essencial do sistema capitalista, vigente na imensa maioria dos países. Essa base fundamental pode ser afetava de diversas maneiras. Duas das principais formas são os subsídios e o crescimento sensível das importações de determinado produto, de sorte a prejudicar seriamente a indústria nacional.

As medidas que visam equilibrar a concorrência afetada são, respectivamente, as medidas compensatórias e as medidas de salvadidas comp
guarda.

É importante ressaltar que nem todos os subsídios são vedados pelo Direito Internacional (GATT/47 e OMC), pelo Direito Interno ou pelo Direito Comunitário. Em geral, somente aqueles que forem específicos, dirigidos à determinada empresa, grupo de empresas ou concedidos com base no resultado das exportações, etc, é que são vedados e, portanto, passíveis de sofrer as medidas compensatórias. Além disso, nem sempre os subsídios representam uma prestação positiva do Estado, isto é, uma despesa pública. Também são considerados subsídios (impróprios) as verdadeiras isenções fiscais, as quais não tem como fundamento apenas uma delimitação da capacidade contributiva, mas representam simplesmente um benefício fiscal, sem ter por base qualquer princípio de justiça distributiva.

As medidas compensatórias, por sua vez são imposições para-tarifárias de direito econômico internacional que visam apenas reequilibrar a livre concorrência, falseada pela concessão de subsídio vedado. Note-se que não basta haver a comprovação de existência de subsídio acionável, para que haja a imposição de medidas compensatórias, é imprescindível que haja também prova do dano à indústria nacional e nexo de causalidade entre este e o benefício concedido.

Por outro lado, as medidas de salvaguarda não têm origem numa má prática comercial, tal qual o dumping ou a concessão de subsídios vedados. As medidas de salvaguarda são restrições temporárias à importação de determinado produto, que vinha sendo importado em determinado volume e sob determinadas condições, de sorte a gerar um dano à indústria do país importador fabricante de produto similar.

É visível, entretanto, que o Direito Internacional voltado ao comércio, refletido na maior parte das vezes no Direito Interno e no Comunitário, vem abrindo espaço também para a proteção de outros princípios, em detrimento do da livre concorrência, exclusivamente, tais como o da proteção ambiental e o da mitigação das desigualdades sociais e econômicas nos diversos países. É possível perceber esse fato, por exemplo, nas permissões a subsídios destinados a atingir esses valores. Contudo, esse movimento é ainda lento e limitado.

\section{Bibliografia}

BAPTISTA, Luiz Olavo. A Organização Mundial do Comércio e suas repercussões sobre o ordenamento jurídico interno. Federação e Centro das Indústrias do Estado de São Paulo - FIESP/CIESP, 1996 
BARRAL, Welber. Subsídios e Medidas Compensatórias na OMC. In CASELLA, Paulo Borba; MERCADANTE, Arminta de Azevedo. Guerra comercial ou integração mundial pelo comércio? A OMC e o Brasil. Ed. LTr, São Paulo, 1998, p. 371/382

CASELLA, Paulo Borba; MERCADANTE, Arminta de Azevedo. Guerra comercial ou integração mundial pelo comércio? A OMC e o Brasil. Ed. LTr, São Paulo, 1998

CELLI JÚNIOR, Umberto. O controle da aplicação das regras de concorrência no processos de integração: a experiência européia (Tese de doutorado defendida na USP). 1997

COSTA, Ligia Maura. OMC - Manual Prático da Rodada Uruguai. Ed. Saraiva, São Paulo, 1996

DEYON, Pierre. O Mercantilismo. Ed. Perspectiva, 1985

FERRAZ JÚNIOR, Tércio Sampaio; ROSA, José Del Chiaro Ferreira da; GRINBERG, Mauro. Direitos anti-dumping e compensatórios: sua natureza juridical e conseqüências de tal caracterização. In Revista de Direito Mercantil, Industrial, Econômico e Financeiro, v. 96, outubro-dezembro, 1994,p. 86-96

FONSECA, João Bosco Leopoldino da. Dire to Econômico. 2 ed, Ed. Forense, Rio de Janeiro, 1998

GRAU, Eros Roberto. A ordem econômica na Constituição de 1988.. 3 ed, Malheiros, São Paulo, 1997

GUEDES, Josefina M. M. M.; PINHEIRO, Silvia M. Anti-dumping, subsídios e medidas compensatórias. Ed. Aduaneiras, 1996

HOLLIDAY, George. The Uruguay Round's Agreement on Safeguards. In In Journal of World Trade, volume 29, June 1995 , Geneve, p. 155/160
LALANNE, Pedro E. Fernández. Prácticas restrictivas de comercio, competencia desleal y dumping en la integración económica centroamericana. In Derecho de la Integración - Revista Jurídica Latinoamericana, v. 20,1 p. 47-77

LEGUILLONS, Henry. Le régime communitaire de protection contre le dumping et les subventions. Feduci - Fundation pour L'Etude du Droit et des Usages du Commerce Internacional, Paris, 1983

LUNARDELLI, Pedro Guilherme Accorsi. Isenções Tributárias. Ed. Dialética, São Paulo, 1999

MEROLLA, Massimo. Direito da concorrência nas Comunidades Europeias - Vol. IIB - Explicação das regras aplicáveis aos auxílios estatais - Situação em dezembro de 1996. Serviço das Publicações Oficiais das ComunidadesEuropéias, Luxemburgo, 1997

Ministério da Fazenda - Comissão de Política Aduaneira. Acordos anti-dumping e de subsídios e medidas compensatórias - princípios gerais e instruções. Rio de Janeiro, 1987

MONCADA, Luis S. Cabral de. Direito Económico., 2 ed, Coimbra Editora Limitada, Coimbra, 1988

PINHEIRO, Silvia; GUEDES, Josefina. Salva guardas no Comércio Internacional. In CASELLA, Paulo Borba; MERCADANTE Arminta de Azevedo. Guerra comercial ou integração mundial pelo comércio? A OMC e o Brasil. Ed.LTr, São Paulo, 1998, p. 330/339

PIRES, Adílson Rodrigues. As práticas abusivas de comércio em mercados desenvolvidos (Tese de doutorado). 1999

RODRIGUES, José Roberto Pernomian. $O$ dumping como forma de expressão do abu so do poder econômico: caracterização e conseqüências. 1999
SANTOS, Antônio Carlos; GONÇALVES, Maria Eduarda; MARQUES, Maria Manuel Leitão. Direito Económico. 3 ed, Almedina, Coimbra, 1998

STEWART, Terence P.; DWYER, Amy. Sunset reviews of antidumping and Countervailing Duty Measures - US Implementation of Uruguay Round Commitments. In Journal of World Trade, volume 32, October 1998, number 5, Geneve,p. 101/135
TORRES, Ricardo Lobo. O orçamento na constituição. Ed. Renovar, Rio de Janeiro, 1995

VALÉRIO, Walter Paldes. Programa de Direito Financeiro e Finanças.5. ed. Ed. Sulina, Porto Alegre, 1995.

YAMACHITA, Douglas. Subsídios \& Isenções. Obra no prelo 